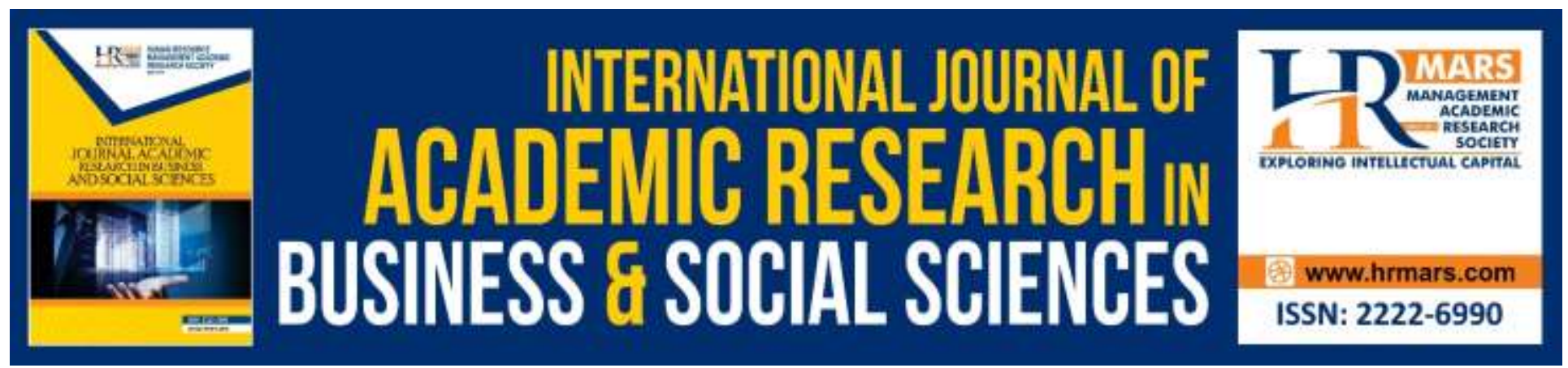

\title{
An Application of Association Rule Mining in Analyzing Courses Affecting the Results of Financial Mathematics Case: UITM Seremban Campus
}

Nur Haidar Hanafi, Diana Juniza Juanis, Muhammad Hilmi Samian, Sarahiza Mohmad, Siti Aishah Mohd Shafie and Siti Nurasyikin Shamsuddin

To Link this Article: http://dx.doi.org/10.6007/IJARBSS/v9-i13/6248

DOI: $10.6007 /$ IJARBSS/v9-i13/6248

Received: 22 March 2019, Revised: 17 June 2019, Accepted: 02 July 2019

Published Online: 23 August 2019

In-Text Citation: (Hanafi et al., 2019)

To Cite this Article: Hanafi, N. H., Juanis, D. J., Samian, M. H., Mohmad, S., Shafie, S. A. M., \& Shamsuddin, S. N. (2019). An Application of Association Rule Mining in Analyzing Courses Affecting the Results of Financial Mathematics Case: UITM Seremban Campus. International Journal of Academic Research in Business and Social Sciences, 9(13), 123-133.

\section{Copyright: (C) 2019 The Author(s)}

Published by Human Resource Management Academic Research Society (www.hrmars.com)

This article is published under the Creative Commons Attribution (CC BY 4.0) license. Anyone may reproduce, distribute, translate and create derivative works of this article (for both commercial and non-commercial purposes), subject to full attribution to the original publication and authors. The full terms of this license may be seen at: http://creativecommons.org/licences/by/4.0/legalcode

Special Issue: Revolutionizing Education: Challenges, Innovation, Collaboration, 2019, Pg. 123 - 133

Full Terms \& Conditions of access and use can be found at http://hrmars.com/index.php/pages/detail/publication-ethics 


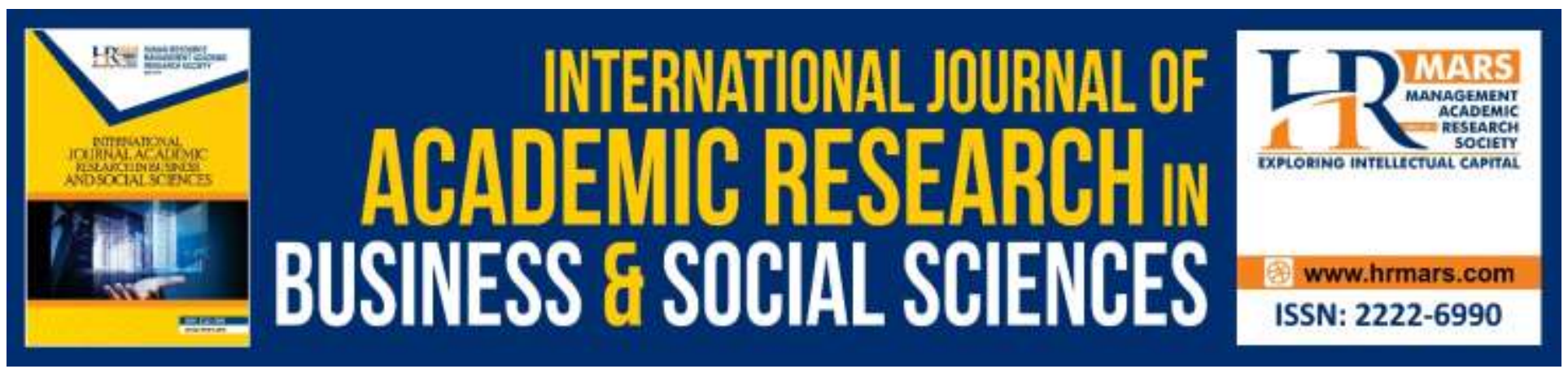

\title{
An Application of Association Rule Mining in Analyzing Courses Affecting the Results of Financial Mathematics Case: UITM Seremban Campus
}

\section{Nur Haidar Hanafi, Diana Juniza Juanis, Muhammad Hilmi Samian, Sarahiza Mohmad, Siti Aishah Mohd Shafie, and Siti Nurasyikin Shamsuddin}

Faculty of Computer and Mathematical Sciences, Universiti Tekonolgi MARA, Negeri Sembilan Branch, Seremban Campus, 70300, Seremban, Negeri Sembilan, Malaysia

\begin{abstract}
Introduction to Financial Mathematics (FM) is one of the subjects that is compulsory to be seated by all students of Diploma in Actuarial Science in UiTM; and is also known as a "killer subject" among the students. Due to this, lecturers are facing problems of high failure rate which exceeds the UiTM's Key Performance Indicator (KPI) by more than $25 \%$ of the students. Thus, the objective of this study is to analyse the courses affecting the results of FM course among the students by using Association Rule Mining. The analysis was carried out only for students who are taking this course for the first time. Out of 360 data gathered, only 273 datasets were employed for the purpose of conducting this study. Results showed that 128 rules were developed and after removing the redundancy, surprisingly 62 interesting rules were found to represent the relationship between all courses and the passing of FM.
\end{abstract}

Keywords: Financial Mathematics, Association Rule Mining, KPI, Data Mining

\section{Background of Studies}

Mathematics is a vital subject. It is very beneficial to human and encloses in their real-life surroundings. Mathematics comes from a large branch of critical thinking disciplinaries and covers all aspects of solving day-to-day problems. The application of mathematics in financial fields is clearly visible especially in analysing the selection of pricing and investment decisions; which in this aspect, mathematics has made remarkable achievements over the year. 
INTERNATIONAL JOURNAL OF ACADEMIC RESEARCH IN BUSINESS AND SOCIAL SCIENCES Vol. 9, No. 13, Special Issue: Revolutionizing Education: Challenges, Innovation, Collaboration., 2019, E-ISSN: 2222-6990 @ 2019 HRMARS One of the programs which require a good comprehensive critical thinking in mathematics is Actuarial Science Studies. In the early 1968, actuarial programs were only available in two universities; Universiti Teknologi Mara (UiTM) and Universiti Kebangsaan Malaysia (UKM). However, increasing awareness on the importance of learning actuarial science has encouraged other universities to offer more undergraduate and postgraduate programs for their students. Furthermore, the demand for the profession in actuarial science field has increased more abruptly and becomes one of the two highest paid jobs in various sectors. Both undergraduate and postgraduate programs in actuarial studies contain a mixture of different technical and theoretical subjects in preparing these students for the actual actuarial practices.

\section{Problem Statement}

Financial Mathematics (ASC303) is a compulsory course taken by Diploma of Actuarial Sciences (CS112) students in UiTM. This course provides a thorough teaching in both aspects of financial areas and relevant mathematics. The course also includes a range of modules in economics, finance, and mathematics; including special modules that deal directly with applications of mathematics in finance. Over the past few years, ASC303 has proven to be one of the toughest courses for CS112 students. Fig.1 below shows the passing and failure rates of ASC303 starting from 2014/2015 session until 2017/2018 session. The failure rates of ASC303 always exceed the KPI of UiTM; which according to the KPI, there must be not more than $25 \%$ of the students fail in any courses.

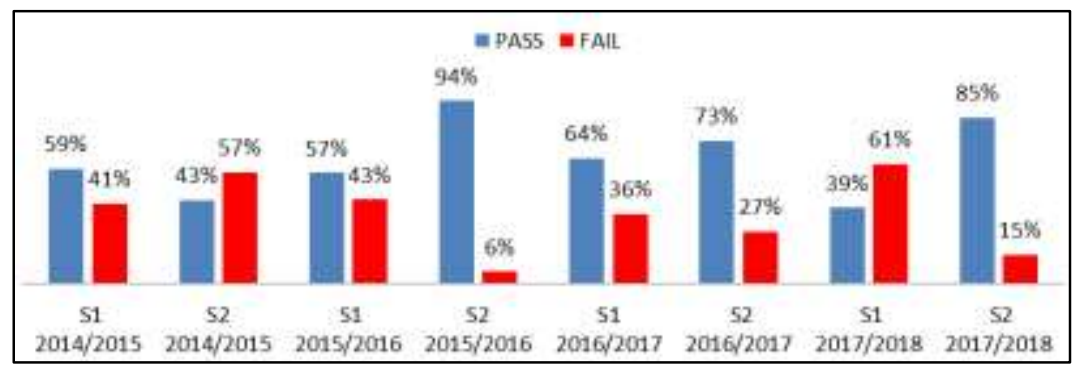

Figure 1 The passing and failure rates of ASC303

Due to the high failure rate problem, the faculty members have been forced to come out with a solid solution to overcome it in order to improve the performance of this program, thus improving the competitiveness of this program with other universities; and also improving the employability of the students.

\section{Objective}

It is believed that the passing of FM course is affected by other courses which the students have to seat prior to this subject. Thus, improving the results of only one subject is only a short-term measurement. Collateral focus should be put on all courses which the students have to seat prior to this subject. Therefore, this study was conducted with the purpose of identifying other courses which contribute to the failure rate of this course; so that the academicians could suggest ways to increase the passing rates by putting attention also to the other courses. In addition, this research study also aimed to categorize whether theoretical courses or technical courses that contribute more to the failure rate of ASC303. 
INTERNATIONAL JOURNAL OF ACADEMIC RESEARCH IN BUSINESS AND SOCIAL SCIENCES

Vol. 9, No. 13, Special Issue: Revolutionizing Education: Challenges, Innovation, Collaboration., 2019, E-ISSN: 2222-6990 @ 2019 HRMARS

\section{Literature Review}

\section{Diploma in Actuarial Science (CS112)}

Diploma in Actuarial Science (CS112) is one of the undergraduate programs offered at the Faculty of Computer and Mathematical Sciences (FSKM), UiTM Seremban Campus. The main objective of this program is to produce graduates who can fulfill the demand of the financial services industries, especially in the insurance industry. The graduates must be equipped with analytical and scientific method skills in the field of actuarial science.

Majority of the diploma holders in this program are hired by the public and the private sectors such as insurance companies, banks and other financial institutions such as security firms. Their tasks include handling statistical investigations and premium pricing. The students will be granted with diploma certificate after they have completed 5 semesters of studies. The list in Table 1 below shows the plan of study for actuarial students up to the fourth semester before they meet financial mathematics course.

Table 1 Plan of Study for Diploma in Actuarial Science

\begin{tabular}{|c|c|c|}
\hline SEMESTER & $\begin{array}{r}\text { COURSE } \\
\text { C } \\
\text { O } \\
\text { D } \\
\text { E }\end{array}$ & COURSES NAME \\
\hline \multirow[t]{7}{*}{1} & ASC 106 & INTRODUCTION TO FINANCIAL ACCOUNTING AND REPORTING \\
\hline & ASC 172 & PRINCIPLE OF RISK MANAGEMENT AND INSURANCE \\
\hline & CSC 119 & FUNDAMENTALS OF COMPUTER SCIENCE \\
\hline & CTU 101 & FUNDAMENTALS OF ISLAM \\
\hline & ELC 120 & INTEGRATED LANGUAGE SKILLS: LISTENING \\
\hline & HBU 111 & NATIONAL KESATRIA 1 \\
\hline & MAT 183 & CALCULUS 1 \\
\hline \multirow[t]{7}{*}{2} & CSC 128 & FUNDAMENTALS OF COMPUTER PROBLEM SOLVING \\
\hline & CTU 151 & ISLAMIC THOUGHT AND CIVILIZATION \\
\hline & ECO 162 & MICROECONOMICS \\
\hline & ELC 150 & INTEGRATED LANGUAGE SKILLS: READING \\
\hline & HBU 121 & NATIONAL KESATRIA II \\
\hline & MAT 233 & CALCULUS II \\
\hline & QMT 161 & INTRODUCTION TO STATISTICS AND PROBABILITY \\
\hline \multirow[t]{6}{*}{3} & CTU 242 & FUNDAMENTAL OF TAKAFUL \\
\hline & ECO 211 & MACROECONOMICS \\
\hline & ELC 230 & INTEGRATED LANGUAGE SKILLS: WRITING \\
\hline & HBU 131 & NATIONAL KESATRIA III \\
\hline & MGT 162 & FUNDAMENTALS OF MANAGEMENT \\
\hline & QMT 211 & MATHEMATICAL STATISTICS \\
\hline 4 & ASC 303 & FINANCIAL MATHEMATICS \\
\hline
\end{tabular}


INTERNATIONAL JOURNAL OF ACADEMIC RESEARCH IN BUSINESS AND SOCIAL SCIENCES Vol. 9, No. 13, Special Issue: Revolutionizing Education: Challenges, Innovation, Collaboration., 2019, E-ISSN: 2222-6990 @ 2019 HRMARS

\section{Financial Mathematics}

Financial Mathematics is one of the courses included in actuarial science studies. This course covers the financial market with an emphasis on mathematical techniques in solving financial problems. It prepares the students for further financial instruments analysis. In order to become a professional actuary, the students need to pass a series of professional examinations. In other countries, as in the U.S, studying mostly occurs during work through a series of examinations. Society of Actuaries (SOA) and Institute and Faculty of Actuaries (IFoA) are among the well-known professional bodies that offer professional exams which encompass different fields. In Malaysia, UiTM receives the exemption from IFoA for their professional papers. One of the courses includes in the exemption is ASC303. Not all students would be granted with the exemption. The exemption depends on the grades they obtained.

\section{Association Rule Mining}

Association Rule Mining (ARM) has become one of the core data mining tasks and has attracted tremendous interest among data mining researchers (Dubey, 2012). ARM looks for interesting associations and/or correlation relationships between large sets of data items. Based on the article written by Chandrakar and Saini (2015), they have highlighted few applications of data mining in higher education studies. One of the applications could be seen in finding the connection between the achievement of different subjects. If there is such a connection, then it allows and facilitates the academicians to prepare for a better lesson plan. Since the association rule mining is one of the processes that can identify any interesting relationships in the datasets, it is very appropriate to use it in any subject performance studies. Through this process, it involves value support, confidence, and lifts which can explain and measure the appropriateness or strength of such relationships.

\section{Methodology}

\section{Sampling Procedure}

The sampling procedure for Association Rule Mining is different than the procedures used in other quantitative studies. The dataset used must represent the actual real-life exposure of the problem. Thus, the dataset used in this study containing the examination results of 360 students from the Diploma in Actuarial Sciences program who had enrolled in UiTM Seremban Campus between June 2014 and January 2018. The data consisted of results for 18 different courses taken by these students in semester 1 until semester 3 prior to taking Financial Mathematics course in semester 4, along with the results for Financial Mathematics. The 18 courses could further be grouped into 2 categories of disciplinary which were theoretical based courses and technical based courses.

\section{Data Preparation}

Since the objective of this study was to analyse the courses affecting the results of Financial Mathematics amongst first-timers, the data of those who took this course more than once were eliminated. Those who had withdrawn from the program prior to taking the course were also eliminated. Hence, the final dataset consisted of the examination results of only 273 students. The dataset was then being converted into a data frame to ease the process of importing the dataset into $\mathrm{R}$ Studio software for rules mining process to be done further. 
INTERNATIONAL JOURNAL OF ACADEMIC RESEARCH IN BUSINESS AND SOCIAL SCIENCES

Vol. 9, No. 13, Special Issue: Revolutionizing Education: Challenges, Innovation, Collaboration., 2019, E-ISSN: 2222-6990 @ 2019 HRMARS

\section{Association Rules Mining}

Table 2 below shows some steps and the description that needs to be done to run Association Rule Mining (ARM) by using the R Studio Software. This process is crucial in order for the software to identify the interesting relationships between the dependent variable and independent variables

Table 2 Command for Association Rule Mining (ARM)

\begin{tabular}{lr}
\hline \multicolumn{1}{c}{ Command } & Description \\
\hline $\begin{array}{l}\text { library(readxl) } \\
\text { ASC303 <- read_excel("ASC303.xIsx") }\end{array}$ & Package excel readxl is used to read the excel file. \\
\hline $\begin{array}{l}\text { EXCELFY <- as.data.frame(ASC303) } \\
\text { library(arules) }\end{array}$ & $\begin{array}{r}\text { The dataset is set as a data frame to ease the ARM } \\
\text { process. All the parameters are set as factors. }\end{array}$ \\
\hline $\begin{array}{l}\text { rules.all <- apriori(ASC303) } \\
\text { quality(rules.all) <- }\end{array}$ & $\begin{array}{r}\text { The rules are found by using apriori technique. Default } \\
\text { setting is used for apriori process. }\end{array}$ \\
\hline $\begin{array}{l}\text { round(quality(rules.all), digits = 7) } \\
\text { inspect(rules.all) }\end{array}$ & Set the quality rules to seven digits. \\
\hline
\end{tabular}

\section{Setting ASC303 as the Right-Hand Side}

The process of mining the rules was done by setting the results of all 18 courses as attributes and the Financial Mathematics results as the right-hand side item. The Apriori algorithm was then employed on the data frame with the threshold for min-support was set to 0.02 . The value of min-support was set lower than usual for the purpose of unveiling any rare rules. Table 3 below shows the steps and the description that needs to be done to run pre-determined ARM.

Table 3 Command for Setting ASC303 as the Right-Hand Side

\begin{tabular}{|c|c|}
\hline Command & Description \\
\hline $\begin{array}{l}\text { rules <- apriori (ASC303, control = list(verbose = } \\
\text { FALSE),parameter = } \\
\text { list(minlen=1, supp=0.02, conf=0.8), } \\
\text { appearance = list(rhs=c("ASC303=A+", } \\
\text { "ASC303=A","ASC303=A-", } \\
\text { "ASC303=B+","ASC303=B","ASC303=B-", } \\
\text { "ASC303=C+","ASC303=C","ASC303=C-", } \\
\text { "ASC303=D+","ASC303=D","ASC303=E", } \\
\text { "ASC303=F"), default = "Ihs")) }\end{array}$ & $\begin{array}{l}\text { Run the apriori processed once again with the new } \\
\text { setting for min-support and confidence } \\
\text { value. The results for ASC } 303 \text { are set as the } \\
\text { right-hand side on the appearance } \\
\text { command. }\end{array}$ \\
\hline quality(rules) <- round(quality(rules), digits = 7) & Set the quality rules to seven decimal places. \\
\hline inspect(rules) & Inspect the rules for any interesting relationships. \\
\hline
\end{tabular}


INTERNATIONAL JOURNAL OF ACADEMIC RESEARCH IN BUSINESS AND SOCIAL SCIENCES

Vol. 9, No. 13, Special Issue: Revolutionizing Education: Challenges, Innovation, Collaboration., 2019, E-ISSN: 2222-6990 @ 2019 HRMARS

\section{Removing Redundancy}

The last step is to remove any redundant rules due to different rules having the same relationships. There are rules being duplicated in the final results due to the nature of ARM in RStudio. If they were not removed, the generalization of this method will be affected.

Table 4 Command and Description to Remove Redundancy

\begin{tabular}{ll}
\multicolumn{1}{c}{ Command } & \multicolumn{1}{c}{ Description } \\
\hline is.redundant(rules) & Check for redundant rules. \\
\hline inspect(rules[!is.redundant(rules)]) & Inspect rules that are not redundant. \\
\hline
\end{tabular}

\section{Results and Discussion}

\section{Association Rules Mining}

There were 128 rules in representing the relationships between the attributes and the righthand side factor had been successfully derived. The accuracy and strength of each relationship were then determined based on the values of confidence and lift, respectively. These values represented the importance of the relationships in representing the effect of each attribute on the right-hand side item; which in this case was the effect of each course on the Financial Mathematics results.

Figure 2 below showed the graph plot of the 128 rules based on the value of their lift. From the graph, it was clearly visible that there were 5 significant subgroups consisting of different combinations of theoretical and technical courses.

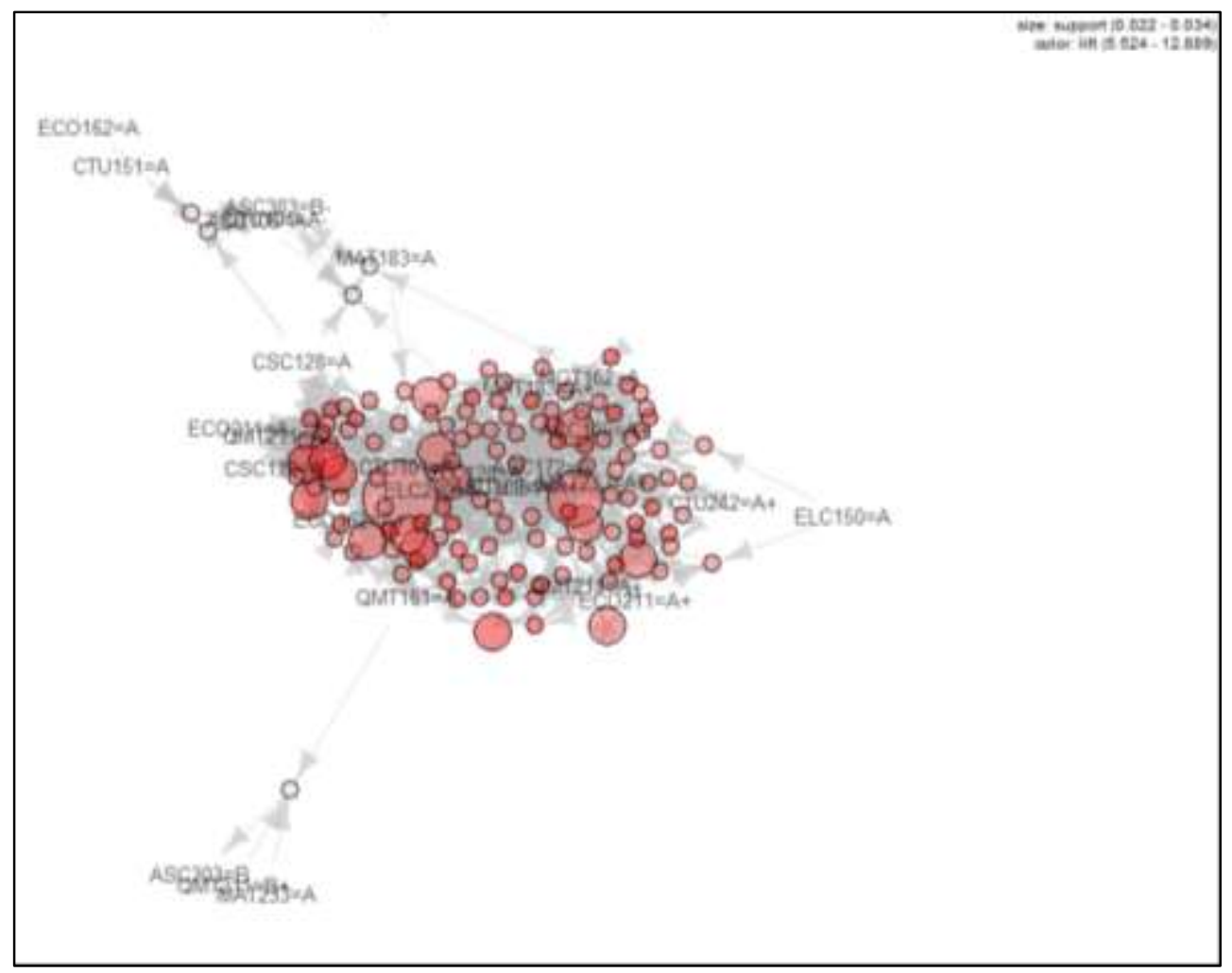

Figure 2 Graph plot of the 128 rules (first stage) 
Inspecting the rules further showed that there were redundant rules generated by the Apriori algorithm, which if not removed will affect the generalization of this method. In order to avoid this, any redundant rules were then removed; leaving only 62 interesting rules worth to be explained further. Fig. 3 below showed the graph plot of the 62 rules based on their values of lift.

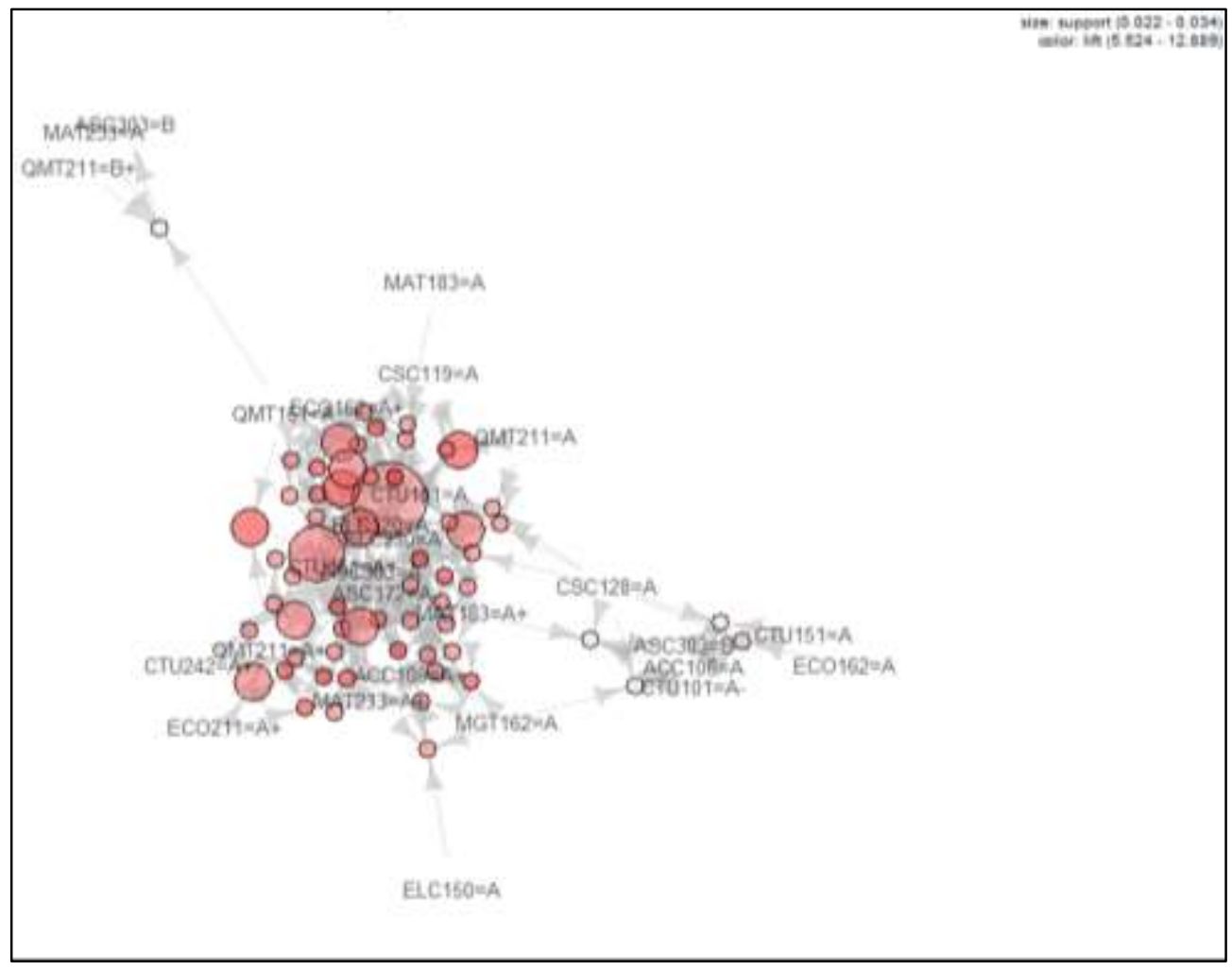

Figure 3 Graph plot of the final 62 rules

\section{Achievement Levels}

Examining the rules further showed that they can be broken down based on students' achievement levels. The students' results were divided into 3 levels namely Excellent, Moderate and Poor. Those who got $A+$ and $A$ in their final examination for Financial Mathematics were considered to be excellent students. Those who got below than $A$ and still passed were considered to be within the moderate level, while those who got $\mathrm{C}$ - and below were failed and need to reseat for the course during the next semester.

\section{Excellent Category}

There were 35 interesting rules included within this category with confidence values ranging from 0.8 to 1.0. Fig. 4 below showed the output obtained from R Studio software by setting grade A+ and $A$ as the right-hand side item. The first rule stated that students who got an A+ in ECO211 and an A+ in QMT211, there was 85\% confidence that they would get an A in Financial Mathematics. On the other hand, the last rule stated that students who got an A in CSC119, CTU101, ELC120, and QMT161, there was $100 \%$ confidence that they would get an A in Financial Mathematics. For lecturers who have aimed for their students to achieve excellent results in Financial Mathematics, they should put 
INTERNATIONAL JOURNAL OF ACADEMIC RESEARCH IN BUSINESS AND SOCIAL SCIENCES Vol. 9, No. 13, Special Issue: Revolutionizing Education: Challenges, Innovation, Collaboration., 2019, E-ISSN: 2222-6990 @ 2019 HRMARS more emphasized on the courses as included in the rules when the students were in semester 1 until semester 3. Early planning can be done in order to increase the number of students within this category.

\begin{tabular}{|c|c|c|c|c|c|c|}
\hline & lhs & & rhs & support & confidence & lift \\
\hline [1] & $\{$ EC0211=A+, QMT211=A+ $\}$ & $\Rightarrow$ & $\{\mathrm{ASC} 303=\mathrm{A}\}$ & 0.02586207 & 0.8571429 & 11.04762 \\
\hline [2] & $\{\mathrm{ACC} 106=\mathrm{A}+, \mathrm{QMT} 211=\mathrm{A}+\}$ & $\Rightarrow$ & $\{$ ASC $303=A\}$ & 0.02155172 & 0.8333333 & 10.74074 \\
\hline [3] & $\{\mathrm{ELC} 230=\mathrm{A}, \mathrm{QMT} 211=\mathrm{A}+\}$ & $\Rightarrow$ & $\{$ ASC $303=A\}$ & 0.02155172 & 0.8333333 & 10.74074 \\
\hline [4] & $\{E L C 120=A, 0 M T 211=A+\}$ & $\Rightarrow$ & $\{\mathrm{ASC} 303=\mathrm{A}\}$ & 0.02155172 & 0.8333333 & 10.74074 \\
\hline [5] & $\{$ QMT161=A, OMT 211=A+ $\}$ & $\Rightarrow$ & $\{$ ASC303=A $\}$ & 0.02586207 & 1.0000000 & 12.88889 \\
\hline [6] & $\{$ ASC172=A, QMT211=A+ $\}$ & $\Rightarrow$ & $\{\mathrm{ASC} 303=\mathrm{A}\}$ & 0.02586207 & 0.8571429 & 11.04762 \\
\hline [7] & $\{\mathrm{ACC} 106=\mathrm{A}+, \mathrm{ECO} 211=\mathrm{A}+, \mathrm{QMT} 211=\mathrm{A}+\}$ & $\Rightarrow$ & $\{$ ASC $303=A\}$ & 0.02155172 & 1.0000000 & 12.88889 \\
\hline [8] & $\{$ ASC172=A, EC0211=A+, QMT211=A+ $\}$ & $\Rightarrow$ & $\{$ ASC303=A $\}$ & 0.02155172 & 1.0000000 & 12.88889 \\
\hline [9] & $\{A C C 106=A+, A S C 172=A$, QMT $211=A+\}$ & $\Rightarrow$ & $\{$ ASC $303=A\}$ & 0.02155172 & 1.0000000 & 12.88889 \\
\hline [10] & $\{$ ASC172=A, MAT233 $=\mathrm{A}+, \mathrm{QMT} 211=\mathrm{A}+\}$ & $\Rightarrow$ & $\{$ ASC $303=A\}$ & 0.02155172 & 1.0000000 & 12.88889 \\
\hline [11] & $\{$ CTU151 $=A+$, MAT233 $=A+$, CTU242 $=A+\}$ & $\Rightarrow$ & $\{$ ASC $303=A\}$ & 0.02155172 & 0.8333333 & 10.74074 \\
\hline [12] & $\{$ ACC106=A+,MAT183=A+, CTU151=A+ $\}$ & $\Rightarrow$ & $\{$ ASC303=A $\}$ & 0.02155172 & 1.0000000 & 12.88889 \\
\hline [13] & $\{$ ACC106 $=A+$, MAT183 $=A+, M G T 162=A\}$ & $\Rightarrow$ & $\{\mathrm{ASC} 303=\mathrm{A}\}$ & 0.02155172 & 1.0000000 & 12.88889 \\
\hline [14] & $\{$ ACC106 $=A+, C T U 101=A, M A T 183=A+\}$ & $\Rightarrow$ & $\{$ ASC $303=A\}$ & 0.02155172 & 0.8333333 & 10.74074 \\
\hline [15] & $\{$ CTU101 $=A, M A T 183=A+, E L C 230=A\}$ & $\Rightarrow$ & $\{A S C 303=A\}$ & 0.02586207 & 0.8571429 & 11.04762 \\
\hline [16] & $\{$ CTU101 $=A, E L C 120=A, M A T 183=A+\}$ & $\Rightarrow$ & $\{A S C 303=A\}$ & 0.02155172 & 0.8333333 & 10.74074 \\
\hline [17] & $\{C T U 151=A+, E C 0162=A+, Q M T 161=A\}$ & $\Rightarrow$ & $\{\mathrm{ASC} 303=\mathrm{A}\}$ & 0.02155172 & 0.8333333 & 10.74074 \\
\hline [18] & $\{$ CTU151 $=A+$, MAT233 $=A+$, ELC230 $=A\}$ & $\Rightarrow$ & $\{A S C 303=A\}$ & 0.02155172 & 0.8333333 & 10.74074 \\
\hline [19] & $\{$ ELC120 $=A, C T U 151=A+$, MAT233 $=A+\}$ & $\Rightarrow$ & $\{\mathrm{ASC} 303=\mathrm{A}\}$ & 0.02586207 & 0.8571429 & 11.04762 \\
\hline [20] & $\{$ ASC172 $=A$, CTU151 $=A+$, MAT233 $=A+\}$ & $\Rightarrow$ & $\{A S C 303=A\}$ & 0.02155172 & 0.8333333 & 10.74074 \\
\hline [21] & $\{C T U 101=A, C T U 151=A+, E L C 230=A\}$ & $\Rightarrow$ & $\{\mathrm{ASC} 303=\mathrm{A}\}$ & 0.03448276 & 0.8000000 & 10.31111 \\
\hline [22] & $\{\mathrm{ELC1} 120=\mathrm{A}, \mathrm{CTU} 151=\mathrm{A}+, \mathrm{QMT} 161=\mathrm{A}\}$ & $\Rightarrow$ & $\{$ ASC303=A $\}$ & 0.02155172 & 0.8333333 & 10.74074 \\
\hline [23] & $\{C$ CSC119=A, ELC120 $=A$, QMT211 $=A\}$ & $\Rightarrow$ & $\{$ ASC $303=A\}$ & 0.02586207 & 1.0000000 & 12.88889 \\
\hline [24] & $\{$ ASC172 $=A, E L C 120=A, M A T 183=A+, C T U 151=A+\}$ & $\Rightarrow$ & $\{$ ASC $303=A\}$ & 0.02155172 & 1.0000000 & 12.88889 \\
\hline [25] & $\{$ ACC106 $=A+, C T U 101=A, M A T 183=A+, E L C 230=A\}$ & $\Rightarrow$ & $\{A S C 303=A\}$ & 0.02155172 & 1.0000000 & 12.88889 \\
\hline [26] & $\{$ ASC172=A, ELC120 $=A, C$ CTU151=A+, MAT233=A+ $\}$ & $\Rightarrow$ & $\{$ ASC $303=A\}$ & 0.02155172 & 1.0000000 & 12.88889 \\
\hline [27] & $\{$ ASC172=A, CTU101=A, CTU151=A+, ELC230 $=A\}$ & $\Rightarrow$ & $\{$ ASC303=A $\}$ & 0.02586207 & 0.8571429 & 11.04762 \\
\hline [28] & $\{$ ACC106 $=A+, M A T 233=A+, E L C 230=A, M G T 162=A\}$ & $\Rightarrow$ & $\{$ ASC303=A $\}$ & 0.02155172 & 0.8333333 & 10.74074 \\
\hline [29] & $\{$ ACC106 $=A+, E L C 120=A, M A T 233=A+, M G T 162=A\}$ & $\Rightarrow$ & $\{\mathrm{ASC} 303=\mathrm{A}\}$ & 0.02155172 & 0.8333333 & 10.74074 \\
\hline [30] & $\{C S C 119=A, E L C 120=A, E C 0162=A+$, QMT161 $=A\}$ & $\Rightarrow$ & $\{$ ASC303=A $\}$ & 0.02155172 & 0.8333333 & 10.74074 \\
\hline [31] & $\{C T U 101=A, E L C 120=A, E C 0162=A+, Q M T 161=A\}$ & $\Rightarrow$ & $\{$ ASC303=A $\}$ & 0.02586207 & 0.8571429 & 11.04762 \\
\hline [32] & $\{C S C 119=A, C T U 101=A, E L C 120=A, E C 0162=A+\}$ & $\Rightarrow$ & $\{$ ASC303=A $\}$ & 0.02155172 & 0.8333333 & 10.74074 \\
\hline [33] & $\{C T U 101=A, C S C 128=A, E L C 230=A, Q M T 211=A\}$ & $\Rightarrow$ & $\{\mathrm{ASC} 303=\mathrm{A}\}$ & 0.02155172 & 0.8333333 & 10.74074 \\
\hline [34] & $\{C S C 119=A, C T U 101=A, E L C 230=A$, QMT211 $=A\}$ & $\Rightarrow$ & $\{$ ASC $303=A\}$ & 0.02155172 & 0.8333333 & 10.74074 \\
\hline [35] & $\{C$ CSC119=A, CTU101=A, ELC120 $=A, E C 0162=A+$, QMT161 $=A\}$ & $\Rightarrow$ & $\{\mathrm{ASC} 303=\mathrm{A}\}$ & 0.02155172 & 1.0000000 & 12.88889 \\
\hline
\end{tabular}

Figure 4 R Studio output for rules with grade $A+$ and $A$

\section{Moderate Category}

There were 17 interesting rules included within this category with confidence values ranging from 0.8 to 1.0. Fig. 5 below showed the output obtained from $R$ Studio software by setting grade $A-, B+$, $B, B-, C+$ and $C$ as the right-hand side item. The first rule stated that those who got $C+$ in MAT233 and $B$ in QMT161, there was an $80 \%$ chance that they would get a $C$ in Financial Mathematics. On the other hand, the last rule stated that students who got an A in ACC106, MAT183, CSC128, CTU151, ECO211, and MGT162, there was 100\% chance that they would get an A- in Financial Mathematics. For students who were predicted to fall into this category, an early interjection by the lecturers could be planned in order to push the students' results to be better than expected. 
INTERNATIONAL JOURNAL OF ACADEMIC RESEARCH IN BUSINESS AND SOCIAL SCIENCES Vol. 9, No. 13, Special Issue: Revolutionizing Education: Challenges, Innovation, Collaboration., 2019, E-ISSN: 2222-6990 @ 2019 HRMARS

\begin{tabular}{|c|c|c|c|c|c|}
\hline & lhs & rhs & support & confidence & lift \\
\hline [1] & $\{$ MAT233=C+, QMT161=B $\}$ & $\Rightarrow\{$ ASC $303=C\}$ & 0.02155172 & 0.8000000 & 6.628571 \\
\hline [2] & $\{\mathrm{CSC} 119=\mathrm{A}-, \mathrm{QMT} 161=\mathrm{A}, \mathrm{QMT} 211=\mathrm{B}+\}$ & $\Rightarrow\{\mathrm{ASC} 303=\mathrm{B}\}$ & 0.02155172 & 1.0000000 & 6.628571 \\
\hline [3] & $\{A C C 106=A-, E L C 120=A-, E C 0162=A-\}$ & $\Rightarrow\{\operatorname{ASC} 303=C\}$ & 0.02155172 & 0.8000000 & 6.628571 \\
\hline [4] & $\{\mathrm{CSC} 119=\mathrm{A}-, \mathrm{ECO} 211=\mathrm{A}, \mathrm{MGT} 162=\mathrm{A}-\}$ & $\Rightarrow\{\operatorname{ASC} 303=C\}$ & 0.02155172 & 0.8000000 & 6.628571 \\
\hline [5] & $\{\mathrm{CSC} 128=\mathrm{B}+, \mathrm{QMT} 161=\mathrm{B}+, \mathrm{CTU} 242=\mathrm{A}-\}$ & $\Rightarrow\{A S C 303=A-\}$ & 0.02155172 & 1.0000000 & 6.628571 \\
\hline [6] & $\{$ MAT233=A, QMT161=A, QMT211=B+ $\}$ & $\Rightarrow\{A S C 303=A-\}$ & 0.02155172 & 0.8333333 & 5.523810 \\
\hline [7] & $\{$ ACC106=A- $, C T U 101=A, M A T 183=A, E C 0162=A\}$ & $\Rightarrow\{A S C 303=B\}$ & 0.02155172 & 0.8000000 & 5.302857 \\
\hline [8] & $\{$ CSC119=A-,$C T U 151=A$, OMT161 $=A, E L C 230=B+\}$ & $\Rightarrow\{\mathrm{ASC} 303=\mathrm{B}\}$ & 0.02155172 & 1.0000000 & 6.628571 \\
\hline [9] & $\{$ ACC106=A, CTU151=A, QMT161=A, ELC230=B+ $\}$ & $\Rightarrow\{\mathrm{ASC} 303=\mathrm{B}\}$ & 0.02155172 & 0.8000000 & 5.302857 \\
\hline [10] & $\{$ ACC106 $=A, A S C 172=A, C T U 101=A-, C S C 128=A\}$ & $\Rightarrow\{\mathrm{ASC} 303=\mathrm{B}-\}$ & 0.02155172 & 0.8333333 & 5.523810 \\
\hline$[11]$ & $\{\mathrm{ACC} 106=\mathrm{A}, \mathrm{CTU} 101=\mathrm{A}-, \mathrm{CSC} 128=\mathrm{A}, \mathrm{MGT} 162=\mathrm{A}\}$ & $\Rightarrow\{\operatorname{ASC} 303=B-\}$ & 0.02155172 & 0.8333333 & 5.523810 \\
\hline$[12]$ & $\{$ ACC106=A, CTU101=A- $, C S C 128=A, C T U 151=A\}$ & $\Rightarrow\{\operatorname{ASC} 303=B-\}$ & 0.02155172 & 0.8333333 & 5.523810 \\
\hline [13] & $\{$ ACC106=A,CTU101=A-, CSC128=A,CTU151=A, EC0162=A $\}$ & $\Rightarrow\{\operatorname{ASC} 303=B-\}$ & 0.02155172 & 1.0000000 & 6.628571 \\
\hline [14] & $\{E L C 120=A, E C 0162=A+, E L C 150=A$, QMT161=A, CTU242=A $\}$ & $\Rightarrow\{\operatorname{ASC} 303=A-\}$ & 0.02155172 & 0.8333333 & 6.628571 \\
\hline$[15]$ & $\{E L C 120=A, C T U 151=A, Q M T 161=A, E C 0211=A, E L C 230=A\}$ & $\Rightarrow\{$ ASC $303=A-\}$ & 0.02155172 & 0.8333333 & 6.628571 \\
\hline$[16]$ & $\{$ ASC172=A, ELC120=A, CSC128=A, CTU151=A, EC0211=A, ELC230=A $\}$ & $\Rightarrow\{\operatorname{ASC} 303=A-\}$ & 0.02155172 & 0.8333333 & 6.628571 \\
\hline$[17]$ & $\{$ ACC106 $=A, M A T 183=A, C S C 128=A, C T U 151=A, E C 0211=A, M G T 162=A\}$ & $\Rightarrow\{\operatorname{ASC} 303=\mathrm{A}-\}$ & 0.02155172 & 1.0000000 & 6.628571 \\
\hline
\end{tabular}

Figure 5 R Studio output for rules with grade A-, B+, B, B-, C+, and C

\section{Poor Category}

There were 10 interesting rules included within this category with confidence values ranging from 0.8 to 1.0. Fig. 6 below showed the output obtained from R Studio software by setting grade C-and lower as the right-hand side item. The first rule stated that those who repeated MAT183 twice and managed to pass with $\mathrm{B}+$, there was $83 \%$ confidence that they would get an $\mathrm{E}$ in Financial Mathematics. On the other hand, the last rule stated that students who got an A in CTU101 and CTU152; a B+ in ELC120 and in CTU242, there was 83\% chance that they would get a D in Financial Mathematics. For students who were predicted to fall into this category, a thorough plan should be carried out in order to ensure that they could perform better and at least get a pass in the final examination.

\begin{tabular}{|c|c|c|c|c|c|c|}
\hline & lhs & & rhs & support & confidence & lift \\
\hline [1] & $\{$ MAT183=2B +$\}$ & $\Rightarrow$ & $\{\mathrm{ASC} 303=\mathrm{E}\}$ & 0.02155172 & 0.8333333 & 33.14286 \\
\hline [2] & $\{$ QMT211=2C $\}$ & $\Rightarrow$ & $\{$ ASC303=F $\}$ & 0.02155172 & 0.8333333 & 33.14286 \\
\hline [3] & $\{$ ASC172=A, MAT233=C $\}$ & $\Rightarrow$ & $\{\mathrm{ASC} 303=\mathrm{C}-\mathrm{\}}$ & 0.02155172 & 1.0000000 & 30.62855 \\
\hline [4] & $\{\mathrm{CSC} 119=\mathrm{B}-, \mathrm{ECO} 211=\mathrm{B}-\}$ & $\Rightarrow$ & $\{$ ASC $303=C-\}$ & 0.02155172 & 1.0000000 & 30.62855 \\
\hline [5] & $\{\mathrm{CSC} 119=\mathrm{B}, \mathrm{CSC} 128=\mathrm{B}-, \mathrm{ELC} 230=\mathrm{B}+\}$ & $\Rightarrow$ & $\{\mathrm{ASC} 303=\mathrm{E}\}$ & 0.02155172 & 0.8333333 & 25.77778 \\
\hline [6] & $\{$ ASC172=B, CSC119=A-, QMT $211=C\}$ & $\Rightarrow$ & $\{$ ASC303 $=D\}$ & 0.02155172 & 0.8333333 & 25.77778 \\
\hline [7] & $\{$ ASC172=B , QMT161=B, QMT211=C $\}$ & $\Rightarrow$ & $\{$ ASC303=D $\}$ & 0.02155172 & 1.0000000 & 23.06068 \\
\hline [8] & $\{\mathrm{CTU} 151=\mathrm{B}+, \mathrm{ELC} 150=\mathrm{A}, \mathrm{MAT} 233=\mathrm{C}\}$ & $\Rightarrow$ & $\{\mathrm{ASC} 303=\mathrm{C}-\}$ & 0.02155172 & 0.8333333 & 21.09091 \\
\hline [9] & $\{\mathrm{EC0} 211=\mathrm{B}+, \mathrm{ELC} 230=\mathrm{B}+, \mathrm{MGT} 162=\mathrm{A}-\}$ & $\Rightarrow$ & $\{\mathrm{ASC} 303=\mathrm{F}\}$ & 0.02155172 & 0.8333333 & 21.09091 \\
\hline$[10]$ & $\{\mathrm{CTU} 101=\mathrm{A}, \mathrm{ELC1} 20=\mathrm{B}+, \mathrm{CTU} 151=\mathrm{A}, \mathrm{CTU} 242=\mathrm{B}+\}$ & $\Rightarrow$ & $\{\mathrm{ASC} 303=\mathrm{D}\}$ & 0.02155172 & 0.8333333 & 21.09091 \\
\hline
\end{tabular}

Figure 6 R Studio output for rules with grade C-, D+, D, E and F 


\section{Conclusion}

The objective of this study had been successfully achieved with 62 interesting rules had been mined by using Association Rules Mining technique with 0.02 min-support. The results from this study provide significant patterns of the courses affecting the results of Financial Mathematics amongst first timers. These patterns can then be used in predicting the future results of the students who will be taking the Financial Mathematics course in semester 4. Based on the patterns, the important courses that should be focused more by the students have been identified. The subjects that occurred most frequently in the rules for all three categories are QMT211, MAT183, and MAT233. These frequent items show that they are the most significant subjects that influent the performance of students for ASC303. For students who have been predicted to fail this subject, the lecturers should take intervention as early as in semester 1.

\section{References}

Algorithm, A. (n.d.). SpringerReference. doi:10.1007/springerreference_178739.

AVidhate, D., \& Kulkarni, P. (2014). Multilevel Relationship Algorithm for Association Rule Mining used for Cooperative Learning. International Journal of Computer Applications, 86(4), 18-27. doi:10.5120/14973-3169.

Chandrakar, O, \& Saini, Jatinderkumar R. (2015). Predicting Examination Results using Association Rule Mining. International Journal of Computer Applications (0975 - 8887) Volume 116-No.1.

Dubey, P. (2012). Association Rule Mining on Distributed Data. International Journal of Scientific \& Engineering Research, Volume 3, Issue 1.

Forfar, D. O. (2006). History of Actuarial Education. Encyclopedia of Actuarial Science.

Kaur, G., \& Aggarwal, S. (2013). A Survey of Genetic Algorithm for Association Rule Mining. International Journal of Computer Applications, 67(20), 25-28. doi:10.5120/115117229.

Khaing, M., \& Thein, N. (2006). An Efficient Association Rule Mining For XML Data. 2006 SICE-ICASE International Joint Conference. doi:10.1109/sice.2006.314676.

Lewin, C. (1987). The Creation of Actuarial Science. The Actuary (July), 36-39.

Rohde, C. A. (2014). Standard Practice of Statistics. Introductory Statistical Inference with the Likelihood Function, 63-65. doi:10.1007/978-3-319-10461-4_6.

Mining, R. (2005). Concept Data Analysis, 141-174. doi:10.1002/0470011297.ch5.

Sawant, V., \& Shah, K. (2016). Performance Evaluation of Distributed Association Rule Mining Algorithms. Procedia Computer Science, 79, 127-134. doi:10.1016/j.procs.2016.03.017. 